\title{
MANFAAT TERAPI REMINISCENCE DALAM MENGATASI DEPRESI PADA LANSIA
}

\author{
Erlina Hermawati*, Iman Permana \\ Program Pascasarjana Magister Keperawatan, Universitas Muhammadiyah Yogyakarta, Jl. Brawijaya, \\ Geblagan, Tamantirto, Kec. Kasihan, Bantul, Daerah Istimewa Yogyakarta, Indonesia 55183 \\ *arsyfakirana5@gmail.com
}

\begin{abstract}
ABSTRAK
Tahapan lansia merupakan tahap akhir dalam kehidupan manusia. Salah satu masalah psikososial yang sering terjadi pada lansia adalah depresi. Terapi reminiscence merupakan salah satu terapi non farmakologis yang dapat menurunkan tingkat depresi lansia. Artikel ini bertujuan untuk mengidentifikasi, mengkritisi dan menganalisa artikel penelitian mengenai manfaat terapi reminiscence pada lansia yang mengalami depresi. Pencarian artikel melalui database seperti Google scholar, Pubmed, Proquest, JSTOR dan EBSCO dengan keywords "geriatric" AND "reminiscence therapy" AND "depression". Tahap pertama pencarian diperoleh 11.420 artikel. Tahap kedua dengan memilih artikel fulltext dan diterbitkan pada tahun 2016 sampai tahun 2019. Tahap ketiga dengan memilih artikel berdasarkan kriteria inklusi. Tahap keempat diperoleh 7 artikel yang memenuhi kriteria inklusi. Penilaian kritis pada artikel menggunakan CASP (Critical Appraisal System Programme). Terdapat dua jenis terapi reminiscence yang dapat dilakukan pada lansia untuk menurunkan depresi yaitu terapi reminiscence yang dilaksanakan secara individu dan berkelompok. Terapi reminiscence dapat bermanfaat dalam menurunkan tingkat depresi pada lansia.
\end{abstract}

Kata kunci: terapi reminiscence, lansia, depresi

\section{BENEFITS OF REMINISCENCE THERAPY TO RESOLVE DEPRESSION ON ELDERLY}

\begin{abstract}
The elderly stage is the final stage in human life. One of the psychosocial problems that often occurs in the elderly is depression. Reminiscence therapy is a non-pharmacological therapy that can reduce the level of depression in the elderly. This article aims to identify, critique and analyze research articles regarding the benefits of reminiscence therapy in the elderly with depression. Search articles through databases such as Google Scholar, Pubmed, Proquest, JSTOR and EBSCO with the keywords "geriatric" AND "reminiscence therapy" AND "depression". The first phase of the search was 11,420 articles. The second stage is by selecting fulltext articles and published in 2016 to 2019. The third stage is by selecting articles based on inclusion criteria. In the fourth step, 7 articles were obtained that met the inclusion criteria. Critical assessment of the article uses CASP (Critical Appraisal System Program). There are two types of reminiscence therapy that can be done in the elderly to reduce depression, namely reminiscence therapy which is carried out individually and in groups. Reminiscence therapy is beneficial in reducing the level of depression in the elderly.
\end{abstract}

Keywords: reminiscence therapy, elderly, depression

\section{PENDAHULUAN}

Masalah penuaan yang sehat menjadi masalah penting secara global. Jumlah lansia yang berusia 65 tahun ke atas di seluruh dunia akan mengalami peningkatan dari 524 juta pada tahun 2010 menjadi 1,5 miliar pada tahun 2050. Menurut Bappenas pada tahun 2015, di Indonesia diperkirakan pada tahun
2010-2030, akan terjadi peningkatan jumlah lansia yang cukup signifikan. Pada tahun 2050 diperkirakan jumlah lansia menjadi 71,6 juta jiwa (Bappenas, 2015). Berdasarkan hasil Susenas pada tahun 2016, jumlah lansia di Indonesia mencapai 22,4 juta jiwa atau $8,69 \%$ dari jumlah penduduk. 
Data menunjukkan bahwa lebih dari $26 \%$ lansia mengalami setidaknya satu gangguan mental atau gangguan neurologis. Gangguan mental yang paling umum terjadi pada lansia adalah demensia, depresi, kecemasan, dan masalah penyalahgunaan zat. Masalah kesehatan, pelayanan sosial, dan perawatan jangka panjang memainkan peran penting dalam mempromosikan kesehatan mental kesehatan pada lansia (WHO, 2015).

Depresi adalah masalah kesehatan mental utama, yang belum diakui sebagai tantangan kesehatan masyarakat yang penting. Sekitar 322 juta orang terkena depresi di seluruh dunia (Friedrich, 2017). Depresi adalah penyumbang tunggal terbesar kecacatan global $(7,5 \%, 2015)$ dan kontributor utama bunuh diri (800.000 per tahun) (WHO, 2017). Depresi di antara populasi lansia akan menjadi penyebab utama beban penyakit di masa depan.

Terapi reminiscence merupakan salah satu terapi yang bisa diterapkan individu maupun kelompok. Terapi ini berupa mengenang masa lalu, mengenang masa kecil, pekerjaan, hobi dan peristiwa lain yang menyenangkan. Mengenang terjadi pada saat kehidupan ketika individu mengalami transisi kehidupan. Meskipun diketahui bahwa lansia akan bernostalgia lebih dari orang yang lebih muda, mengenang adalah sesuatu yang semua orang bisa lakukan untuk sebagian besar hidup mereka. Lansia mungkin melihat ke masa lalu untuk melanjutkan kesinambungan pribadi. Para lansia yang merasa bahwa hidup mereka tanpa tujuan cenderung beralih ke kenang-kenangan. Sebagian besar waktu mengenang masa lalu dapat membantu mereka menemukan arti atau makna kehidupan (Latha dkk., 2014).

Terapi reminiscence merupakan intervensi yang efektif biayanya untuk menurunkan depresi pada wanita yang tinggal di panti wredha yang lama, karena terapi ini relatif mudah untuk diimplementasikan dan prosedurnya mempunyai efek samping membahayakan yang minimal (Jones, 2003). Literature review artikel ini bertujuan untuk menganalisa dan mengkritisi artikel penelitian yang berkaitan dengan terapi reminiscence pada lansia yang mengalami depresi yang terjadi di berbagai wilayah dunia yang diperoleh melalui berbagai sumber database.

\section{METODE}

Metode yang digunakan dalam penulisan literature review ini adalah dengan mencari artikel mengenai terapi reminiscence pada lansia dengan depresi melalui database seperti Google scholar, Pubmed, Proquest, JSTOR dan EBSCO dengan keywords "geriatric" AND "reminiscence therapy" $A N D$ "depression" yang diterbitkan 2 tahun terakhir (tahun 2016-2019) dan melakukan analisa serta telaah artikel dengan menggunakan CASP (Critical Appraisal System Programme), selanjutnya artikel yang sesuai dengan kriteria dilakukan analisis dan telaah secara mendalam.

Proses pengumpulan data dilakukan dengan penyaringan dari berbagai sumber artikel menjadi 7 artikel berdasarkan kriteria yang ditentukan oleh Penulis. Penulis melakukan pencarian artikel melalui Google Scholar, Pubmed (www.ncbi.nlm.nih.gov/pubmed), Proquest, JSTOR, dan EBSCO, dengan keywords "geriatric" AND "reminiscence therapy" AND "depression". Penulis melakukan penyaringan artikel dengan menentukan kriteria inklusi dan kriteria eksklusi. Kriteria inklusi dalam penyaringan artikel ini adalah artikel yang berkaitan dengan terapi reminiscence pada lansia dengan depresi, jurnal/artikel yang diterbitkan pada 01 Januari 2016 - Agustus 2019, merupakan Original article dan full text dan berupa penelitian kuantitatif, sedangkan untuk kriteria eksklusi meliputi artikel yang menggunakan bahasa selain bahasa Inggris dan depresi pada remaja atau dewasa.

Strategi dalam pencarian literatur ini meliputi 4 tahap. Tahap pertama pencarian diperoleh 11.420 artikel. Tahap kedua dengan memilih artikel fulltext dan diterbitkan pada tahun 2016 sampai tahun 2019 dan diperoleh 3.295 artikel,. Tahap ketiga dengan memilih artikel berdasarkan kriteria inklusi sejumlah 314 artikel. Tahap keempat diperoleh 7 artikel yang layak untuk dilakukan telaah secara mendalam. 
HASIL

Adapun hasil literatur review disampaikan pada tabel 1 .

Tabel 1.

Studi Karakteristik Literatur

\begin{tabular}{|c|c|c|c|c|c|c|c|}
\hline No & $\begin{array}{c}\text { Peneliti dan } \\
\text { tahun }\end{array}$ & $\begin{array}{c}\text { Design } \\
\text { penelitian }\end{array}$ & $\begin{array}{c}\text { Tujuan } \\
\text { penelitian }\end{array}$ & Sampel & Instrumen & $\begin{array}{c}\text { Intervens } \\
\mathrm{i} \\
\end{array}$ & Hasil \\
\hline 1. & $\begin{array}{l}\text { (Tarugu } \\
\text { dkk., 2019) }\end{array}$ & $\begin{array}{l}\text { quasi- } \\
\text { experiment }\end{array}$ & $\begin{array}{l}\text { untuk } \\
\text { mengetahui } \\
\text { pengaruh } \\
\text { terapi } \\
\text { reminiscence } \\
\text { dalam } \\
\text { mengurangi } \\
\text { tingkat } \\
\text { kesepian, } \\
\text { gejala depresi, } \\
\text { dan } \\
\text { kecemasan } \\
\text { pada lansia. }\end{array}$ & $\begin{array}{l}27 \text { lansia } \\
\text { di India }\end{array}$ & $\begin{array}{l}\text { UCLA, } \\
\text { Geriatric } \\
\text { Depression } \\
\text { Scale, } \\
\text { Geriatric } \\
\text { Anxiety Scale } \\
\text { Respectively }\end{array}$ & 6 sesi & $\begin{array}{l}\text { Terapi } \\
\text { reminiscence } \\
\text { dapat } \\
\text { menurunkan } \\
\text { kecemasan, } \\
\text { depresi dan } \\
\text { kesepian pada } \\
\text { lansia. }\end{array}$ \\
\hline 2. & $\begin{array}{l}\text { (Lök dkk., } \\
\text { 2019) }\end{array}$ & RCT & $\begin{array}{l}\text { untuk } \\
\text { mengetahui } \\
\text { efek terapi } \\
\text { reminiscence } \\
\text { pada fungsi } \\
\text { kognitif, } \\
\text { depresi, dan } \\
\text { kualitas hidup } \\
\text { pada lansia } \\
\text { dengan } \\
\text { penyakit } \\
\text { Alzheimer. }\end{array}$ & $\begin{array}{l}60 \text { lansia } \\
\text { di Turki }\end{array}$ & $\begin{array}{l}\text { SMMSE, } \\
\text { Cornell Scale } \\
\text { for Depression } \\
\text { in Dementia, } \\
Q O L-A D\end{array}$ & $\begin{array}{l}\text { Terapi } \\
\text { dilaksana } \\
\text { kan } \\
\text { semingg } \\
\text { u sekali } \\
\text { selama } 8 \\
\text { minggu. } \\
\text { Setiap } \\
\text { sesi } 60 \\
\text { menit, } \\
\text { setiap } \\
\text { kelompo } \\
\text { k terdiri } \\
\text { dari } 6 \\
\text { lansia }\end{array}$ & $\begin{array}{l}\text { Terapi } \\
\text { reminiscence } \\
\text { yang } \\
\text { dilaksanakan } \\
\text { secara teratur } \\
\text { dapat } \\
\text { meningkatkan } \\
\text { fungsi } \\
\text { kognitif, } \\
\text { menurunkan } \\
\text { gejala } \\
\text { depresi, dan } \\
\text { meningkatkan } \\
\text { kualitas hidup } \\
\text { pada lansia } \\
\text { dengan } \\
\text { Alzheimer }\end{array}$ \\
\hline 3. & $\begin{array}{l}\text { (Devi, } \\
\text { 2019) }\end{array}$ & $\begin{array}{l}\text { Studi pra } \\
\text { eksperimen }\end{array}$ & $\begin{array}{l}\text { Untuk } \\
\text { mengetahui } \\
\text { efektivitas } \\
\text { psikoterapi } \\
\text { reminiscence } \\
\text { terstruktur } \\
\text { pada tingkat } \\
\text { depresi lansia. }\end{array}$ & $\begin{array}{lr}60 & \text { lansia } \\
\text { usia } & 60-80 \\
\text { tahun } & \text { di } \\
\text { India }\end{array}$ & $\begin{array}{l}\text { Depression } \\
\text { Beck }\end{array}$ & $\begin{array}{l}\text { Tidak } \\
\text { dijelaska } \\
\mathrm{n}\end{array}$ & $\begin{array}{l}\text { Psikoterapi } \\
\text { reminiscence } \\
\text { terstruktur } \\
\text { efektif untuk } \\
\text { mengurangi } \\
\text { tingkat } \\
\text { depresi lansia }\end{array}$ \\
\hline 4. & $\begin{array}{l}\text { (Siverová \& } \\
\text { Bužgová, } \\
\text { 2018) }\end{array}$ & $\begin{array}{l}\text { Quasi } \\
\text { eksperimen } \\
\text { dengan pre } \\
\text { test post test } \\
\text { dengan } \\
\text { kelompok } \\
\text { kontrol }\end{array}$ & $\begin{array}{l}\text { Untuk } \\
\text { menganalisis } \\
\text { pengaruh } \\
\text { terapi } \\
\text { kelompok } \\
\text { narasi } \\
\text { reminiscence } \\
\text { pada kognitif, } \\
\text { kualitas hidup, } \\
\text { sikap terhadap } \\
\text { penuaan, dan } \\
\text { gejala depresi } \\
\text { pada lansia } \\
\text { dengan } \\
\text { gangguan }\end{array}$ & $\begin{array}{l}\text { Kelompok } \\
\text { perlakuan } \\
59 \\
\text { Kelompok } \\
\text { kontrol } 57\end{array}$ & $\begin{array}{l}\text { WOHQOL- } \\
\text { BREF, } \\
\text { WHOQOL- } \\
\text { OLD, GDS, } \\
\text { MMSE, AAQ }\end{array}$ & $\begin{array}{l}\text { Semingg } \\
\text { u sekali } \\
\text { dalam } 8 \\
\text { minggu }\end{array}$ & $\begin{array}{l}\text { Terapi } \\
\text { kelompok } \\
\text { narasi } \\
\text { reminiscence } \\
\text { secara positif } \\
\text { mempengaru } \\
\text { hi, kualitas } \\
\text { hidup, sikap } \\
\text { terhadap } \\
\text { penuaan, dan } \\
\text { gejala depresi } \\
\text { pada lansia } \\
\text { dengan } \\
\text { gangguan } \\
\text { kognitif. }\end{array}$ \\
\hline
\end{tabular}




\begin{tabular}{|c|c|c|c|c|c|c|c|}
\hline & & & kognitif. & & & & \\
\hline 5. & $\begin{array}{ll}\text { (Wu dkk., } \\
\text { 2018) }\end{array}$ & $\begin{array}{l}\text { One-group } \\
\text { pretest- } \\
\text { posttest } \\
\text { design. }\end{array}$ & $\begin{array}{l}\text { Menguji } \\
\text { keefektifan } \\
\text { terapi } \\
\text { reminiscence } \\
\text { individu pada } \\
\text { lansia wanita } \\
\text { yang tinggal di } \\
\text { komunitas } \\
\text { dengan gejala } \\
\text { depresi. }\end{array}$ & 27 lansia & $\begin{array}{l}\text { Geriatric } \\
\text { Depression } \\
\text { Scale, Zung } \\
\text { Self-rating } \\
\text { Anxiety Scale, } \\
\text { Reminiscence } \\
\text { Functions } \\
\text { Scale and } \\
\text { Cognitive } \\
\text { Emotion } \\
\text { Regulation } \\
\text { Questionnaire }\end{array}$ & $\begin{array}{l}\text { Terapi } \\
\text { individu } \\
\text { Selama } \\
6 \text { minggu }\end{array}$ & $\begin{array}{l}\text { Terapi } \\
\text { reminiscence } \\
\text { individu } \\
\text { dapat } \\
\text { meghilangkan } \\
\text { depresi dan } \\
\text { kecemasan }\end{array}$ \\
\hline 6. & $\begin{array}{l}\text { (Viguer } \\
\text { dkk., 2017) }\end{array}$ & $\begin{array}{l}\text { Quasi } \\
\text { eksperimen } \\
\text { dengan pre } \\
\text { test post test } \\
\text { dengan } \\
\text { kelompok } \\
\text { kontrol }\end{array}$ & $\begin{array}{l}\text { Untuk } \\
\text { mengetahui } \\
\text { intervensi } \\
\text { reminiscence } \\
\text { dalam } \\
\text { mengurangi } \\
\text { depresi dan } \\
\text { meningkatkan } \\
\text { kepuasan } \\
\text { hidup dan } \\
\text { kesejahteraan } \\
\text { psikologis } \\
\text { pada lansia. }\end{array}$ & $\begin{array}{l}80 \text { lansia } \\
\text { kelompok } \\
\text { perlakuan, } \\
80 \text { lansia } \\
\text { kelompok } \\
\text { kontrol } \\
160 \text { lansia } \\
\text { di } \\
\text { Republik } \\
\text { Dominikus }\end{array}$ & $\begin{array}{l}G D S \\
\text { Life } \\
\text { Satisfaction } \\
\text { Index-A } \\
\text { Psychological } \\
\text { Well-Being } \\
\text { Scales }\end{array}$ & $\begin{array}{l}10 \text { sesi } \\
\text { selama } 3 \\
\text { bulan }\end{array}$ & $\begin{array}{l}\text { Terapi } \\
\text { reminiscence } \\
\text { berguna } \\
\text { untuk } \\
\text { mengurangi } \\
\text { depresi dan } \\
\text { meningkatkan } \\
\text { kepuasan } \\
\text { hidup dan } \\
\text { meningkatkan } \\
\text { tingkat } \\
\text { kesejahteraan } \\
\text { pada lansia. }\end{array}$ \\
\hline 7. & $\begin{array}{l}\text { (Duru } \\
\text { Aşiret, } \\
\text { Kapucu, } \\
\text { 2016) }\end{array}$ & $\begin{array}{l}\text { Quasi } \\
\text { eksperimen }\end{array}$ & $\begin{array}{l}\text { untuk } \\
\text { mengetahui } \\
\text { efek terapi } \\
\text { reminiscence } \\
\text { pada kognisi, } \\
\text { depresi, } \\
\text { aktivitas hidup } \\
\text { sehari-hari } \\
\text { pasien } \\
\text { Alzheimer } \\
\text { ringan dan } \\
\text { sedang }\end{array}$ & $\begin{array}{l}62 \text { lansia } \\
\text { yang } \\
\text { terdiri dari } \\
31 \quad \text { lansia } \\
\text { kelompok } \\
\text { intervensi } \\
\text { dan } 31 \\
\text { lansia } \\
\text { kelompok } \\
\text { kontrol. } \\
\text { Di Ankar, } \\
\text { Turki }\end{array}$ & $\begin{array}{l}\text { Activities of } \\
\text { Daily Living } \\
\text { Follow-up } \\
\text { Form, } \\
\text { Standardized } \\
\text { Mini Mental } \\
\text { Test and } \\
\text { Geriatric } \\
\text { Depression } \\
\text { Scale }\end{array}$ & $\begin{array}{l}\text { Terapi } \\
\text { reminisc } \\
\text { ence } \\
\text { diadakan } \\
\text { selama } \\
12 \\
\text { minggu, } \\
\text { dilaksana } \\
\text { kan } \\
\text { semingg } \\
\text { u sekali } \\
\text { dengan } \\
\text { durasi } \\
30-35 \\
\text { menit } \\
\text { dengan } \\
\text { kelompo } \\
\mathrm{k} \quad \text { yang } \\
\text { terdiri } \\
\text { dari 4-5 } \\
\text { lansia. }\end{array}$ & $\begin{array}{l}\text { Terapi } \\
\text { reminiscence } \\
\text { dapat } \\
\text { meningkatkan } \\
\text { kognisi dan } \\
\text { menurunkan } \\
\text { depresi pada } \\
\text { kelompok } \\
\text { intervensi. }\end{array}$ \\
\hline & $\begin{array}{l}\text { rkan } 7 \\
\text { ketahui b }\end{array}$ & $\begin{array}{l}\text { ikel } \\
\text { wa: }\end{array}$ & ditelaah & $\begin{array}{l}\text { 2018) } \\
\text { remini }\end{array}$ & $\begin{array}{l}\text { mengguna } \\
\text { ence sejuml }\end{array}$ & $\begin{array}{l}\text { terapi } \\
27 \text { lansia }\end{array}$ & $\begin{array}{l}\text { individu } \\
\text { rempuan. }\end{array}$ \\
\hline
\end{tabular}

1. Jumlah peserta terapi reminiscence

Dari 7 artikel yang ditelaah 5 artikel tidak menjelaskan besar sampel yang digunakan dalam terapi kelompok reminiscence, sedangkan artikel (Lök dkk., 2019) menggunakan 6 lansia dalam satu kelompok, artikel (Duru Aşiret \& Kapucu, 2016) menggunakan 4-5 lansia dalam satu kelompok, sedangkan artikel (Wu dkk.,

\section{Jenis terapi reminiscence}

Dari 7 artikel yang ditelaah diperoleh 5 artikel menggunakan terapi reminiscence yang dilaksanakan secara berkelompok, 1 artikel menggunakan terapi reminiscence secara individu dan 1 artikel tidak menjelaskan prosedur terapi reminiscence.

\section{Frekuensi}


Dari 7 artikel yang ditelaah, didapatkan artikel (Viguer dkk., 2017) melaksanakan terapi reminiscence sebanyak 10 sesi selama 3 bulan, artikel (Tarugu dkk., 2019) tsebanyak 6 sesi, artikel (Wu dkk., 2018) melakukan intervensi terapi individu reminiscence selama 6 minggu.

\section{Responden}

Berdasarkan 7 artikel dapat diketahui bahwa responden yang diteliti (Duru Aşiret \& Kapucu, 2016) dan (Lök dkk., 2019) adalah lansia yang menderita penyakit Alzheimer. Responden yang diteliti (Wu dkk., 2018) adalah lansia perempuan yang berusia $>60$ tahun yang mengalami depresi dengan skor 11-25. Artikel (Viguer dkk., 2017) menggunakan 160 lansia yang dibagi menjadi 2 kelompok perlakuaan yaitu lansia yang berusia di atas 65 tahun dan mengalami gangguan kognitif. (Siverová \& Bužgová, 2018) meneliti responden lansia dengan gangguan kognitif, sedangkan 2 artikel lain menggunakan responden lansia yang mengalami depresi secara umum.

\section{PEMBAHASAN}

Terapi reminiscence dapat mencakup berbagai teknik yang digunakan oleh para profesional dan non-profesional dalam pengaturan yang berbeda. Terapi reminiscence ini dapat dilaksanakan di rumah sakit, kelompok masyarakat, dan program lainnya. Terapi reminiscence efektivitas digunakan pada lansia yang mengalami defisit kognitif seperti penyakit Alzheimer, depresi, atau masalah mental lainnya (Latha dkk., 2014). Pada dasarnya reminiscence dan life review telah ditemukan untuk meningkatkan kepuasan hidup, menurunkan atau mencegah depresi, meningkatkan interaksi sosial, mengurangi rasa sakit kronis, membantu dengan orientasi kognitif dan meningkatkan hubungan antar keluarga (Latha dkk., 2014).

Terapi reminiscence telah terbukti bermanfaat bagi para lansia karena mengurangi depresi dan perasaan negatif. Ini juga meningkatkan integrasi diri. Menurut literatur, terapi kenang-kenangan biasanya diberikan kepada orang tua dengan depresi sekitar 6-12 kali, 1-2 kali seminggu, dan dalam sesi 40-60 menit (35-38). Ini juga digunakan dalam intervensi dalam kondisi dan situasi lain sebagai intervensi terapeutik untuk depresi (Latha dkk., 2014).

Reminiscence memungkinkan pikiran dan ingatan seseorang untuk dirangsang dan memberikan rasa kesinambungan pada "kehidupan yang diingat". Meninjau kehidupan kita dan menceritakan kisah-kisah kita membuat kita merasa puas dengan kehidupan dan benar-benar menghubungkan masa lalu kita dengan masa kini dan satu generasi ke generasi lainnya. Reminiscence telah dilihat sebagai kegiatan terapi yang bermanfaat dan berpotensi untuk orang-orang dari segala usia. Namun ada kebutuhan untuk lebih banyak studi kasus terkontrol untuk membuktikan efektivitas jangka panjang yang sama (Latha dkk., 2014).

Reminiscence adalah pengobatan non-invasif yang baik untuk pencegahan dan pengobatan penyakit mental pada lansia di Taiwan (Yen \& Lin, 2018). Depresi ringan pada lansia dapat diturunkan melalui terapi reminiscence secara individu (Poorneselvan \& Steefel, 2014). Terapi Reminiscence (RT) adalah salah satu perawatan psikologis yang terbaik untuk merawat lansia dengan depresi (Pinquart \& Forstmeier, 2012).

\section{SIMPULAN}

Berdasarkan 7 artikel yang dianalisa maka dapat diambil kesimpulan bahwa terapi reminiscence dapat bermanfaat dalam menurunkan tingkat depresi pada lansia.

\section{DAFTAR PUSTAKA}

Bappenas. (2015). Laporan Pencapaian Tujuan Pembangunan Milenium di Indonesia 2014. Jakarta.

Devi, R. (2019). A Pre-Experimental Study to Evaluate the Effectiveness of Structured Reminiscence Psychotherapy on the Level of Depression among Elderly Residing in Old Age Hom. Int. J. Nur. Edu. and Research., 7(2), 183-185. https://doi.org/10.5958/24542660.2019.00039.5

Duru Aşiret, G., \& Kapucu, S. (2016). The Effect of Reminiscence Therapy on Cognition, Depression, and Activities of Daily Living for Patients With Alzheimer Disease. Journal of 
Geriatric Psychiatry and Neurology, 29(1), 31-37. https://doi.org/10.1177/089198871559 8233

Friedrich, M. (2017). Depression is the leading cause of disability around the world. Jama, 317(15), 1517.

Jones, E. D. (2003). Reminiscence therapy for older women with depression. Journal of Gerontological Nursing. http://proquest.umi.com

Latha, K. S., Bhandary, P. V., Tejaswini, S., \& Sahana, M. (2014). Reminiscence Therapy: An Overview. Middle East Journal of Age and Ageing, 11(1), 1822.

https://doi.org/10.5742/MEAA.2014.9 2393

Lök, N., Bademli, K., \& Selçuk-Tosun, A. (2019). The effect of reminiscence therapy on cognitive functions, depression, and quality of life in Alzheimer patients: Randomized controlled trial. International Journal of Geriatric Psychiatry, 34(1), 47-53. https://doi.org/10.1002/gps.4980

Pinquart, M., \& Forstmeier, S. (2012). Effects of reminiscence interventions on psychosocial outcomes: A metaanalysis. Aging \& Mental Health, 16(5), 541-558. https://doi.org/10.1080/13607863.2011 .651434

Poorneselvan, C., \& Steefel, L. (2014). The Effect of Individual Reminiscence Therapy on Self-Esteem and Depression Among Institutionalized Elderly in India. Creative Nursing, 20(3), 183-190. https://doi.org/10.1891/10784535.20.3.183

Siverová, J., \& Bužgová, R. (2018). The effect of reminiscence therapy on quality of life, attitudes to ageing, and depressive symptoms in institutionalized elderly adults with cognitive impairment: A quasiexperimental study. International Journal of Mental Health Nursing, 27(5), 1430-1439. https://doi.org/10.1111/inm.12442
Tarugu, J., Pavithra, R., Vinothchandar, S., Basu, A., Chaudhuri, S., \& John, K. R. (2019). Effectiveness of structured group reminiscence therapy in decreasing the feelings of loneliness, depressive symptoms and anxiety among inmates of a residential home for the elderly in Chittoor district. International Journal of Community Medicine And Public Health, 6(2), 847. https://doi.org/10.18203/23946040.ijcmph20190218

Viguer, P., Satorres, E., Fortuna, F. B., \& Meléndez, J. C. (2017). A Follow-Up Study of a Reminiscence Intervention and Its Effects on Depressed Mood, Life Satisfaction, and Well-Being in the Elderly. The Journal of Psychology, 151(8), 789-803. https://doi.org/10.1080/00223980.2017 .1393379

WHO. (2017). Depression and other common mental disorders: Global health estimate. Geneva.

World Health Organization. (2015). Mental health and older adults. Fact Sheet $\mathrm{N}^{\circ} 381$.

Wu, D., Chen, T., Yang, H., Gong, Q., \& Hu, X. (2018). Verbal responses, depressive symptoms, reminiscence functions and cognitive emotion regulation in older women receiving individual reminiscence therapy. Journal of Clinical Nursing, 27(1314), 2609-2619. https://doi.org/10.1111/jocn.14156

Yen, H.-Y., \& Lin, L.-J. (2018). A Systematic Review of Reminiscence Therapy for Older Adults in Taiwan: Journal of Nursing Research, 26(2), 138-150. https://doi.org/10.1097/jnr.000000000 0000233 